\title{
MYOCARDIAL INFARCTION WITHOUT OBSTRUCTIVE CORONARY DISEASE: ROLE OF IMAGES
}

Vitorino Modesto dos Santos, Laura Campos Modesto

Medical Course at the University Center of Brasília (Uniceub), Brasília, DF. E-mail: vitorinomodesto@gmail.com

\begin{abstract}
This manuscript about myocardial infarction with nonobstructive coronary arteries (MINOCA) based on published studies aims to enhance the awareness of primary health workers about this potentially serious condition that often poses diagnostic challenges. Two Brazilian, one Chilean, and one Turkish studies are commented on, and the role of imaging evaluations to establish the diagnosis is emphasized.
\end{abstract}

Keywords: Myocardial Infarction without Coronary Obstruction, MINOCA, Diagnosis, Epidemiology, Images.

\section{INFARTO DO MIOCÁRDIO SEM DOENÇA CORONARIANA OBSTRUTIVA: PAPEL DAS IMAGENS}

\section{Resumo}

Este manuscrito sobre infarto do miocárdio com artérias coronárias não obstrutivas (MINOCA) com base em estudos publicados tem como objetivo aumentar a conscientização dos profissionais de saúde primários sobre esta condição potencialmente grave que muitas vezes apresenta desafios diagnósticos. Dois estudos brasileiros, um chileno, e um turco são comentados, e o papel das avaliações por imagem para estabelecer o diagnóstico é enfatizado.

Palavras-chave: Infarto do miocárdio sem obstrução coronariana, MINOCA, Diagnóstico, Imagens.

Dear Editor,

Myocardial infarction with nonobstructive coronary arteries (MINOCA) is a condition characterized by acute myocardial infarction (AMI) without obstruction on coronary angiography studies. The diagnostic criteria for AMI are fulfilled, but at least half of the patients do not present with significant images of obstructive disease ${ }^{1-4}$. Recently, we read in this Journal the article by Grigoli and Viccechi about MINOCA ${ }^{1}$. They reviewed 12 articles in English from 2017 to 2019 describing epidemiological and clinical features, and the management options for this challenging entity. MINOCA was detected among $5 \%$ to $7 \%$ of patients with AMI submitted to coronary angiography. And in an observational and multicenter cohort study, the authors found a $40 \%$ probability of MINOCA through a score based on the standard variables at hospital admission ${ }^{1}$. They also found predominance among elderly men, although some studies show a higher frequency in women. Besides, there was a lower incidence of cardiovascular risks when compared to patients with AMI and coronary obstruction. The number of MINOCA diagnosed cases was higher during the summer and autumn months, and especially during the morning periods. Tobacco smoking, high blood pressure, kidney disease, previous AMI, and stroke are factors associated with the development of MINOCA 1. There was no consensus about differences of prognosis between MINOCA and AMI due to coronary obstruction. Treatment with statins resulted in less impairment of the functional class (14.3\% vs 56.9\%), and the use of beta-blockers provided a reduction in cardiovascular events ( $2.7 \%$ vs $26.7 \%)$. The authors suggested that the management with antihypertensive and antiplatelet drugs merit further randomized clinical assays to confirm their efficacy for better prognosis ${ }^{1}$. 
Asil et al, retrospectively studied a cohort of 3855 patients with AMI from 2016 to 2019, and 4\% had the diagnosis of MINOCA. They reported demographic, clinical, and angiographic data and compared the causes and pathophysiological mechanisms ${ }^{2}$. There was no difference between genders, the mean age was 55 years, and the causes were plaque disruption (48.4\%), micro vascular dysfunction, slow flow and arrhythmia. They compared plaque disruption with other causes and found that age ( 58.31 vs 51.89 years), hypertension ( $48.7 \%$ vs $31.6 \%)$, prior coronary artery disease $(21.1 \%$ vs $2.5 \%)$ and creatinine clearance ( 67.35 vs 74.0 ) were higher in cases of plaque disruption ${ }^{2}$. Coronary angiograms were normal in $29 \%$ of the patients, while $56 \%$ showed plaques and less than $50 \%$ of stenosis. This concept of normal artery includes completely normal coronaries without plaque, wall irregularity, slow flow, vasospasm, dissection, and thrombus. Cardiac magnetic resonance (CMR) was not done in all cases due to local limitations. They concluded that MINOCA is a diagnosis of exclusion with many potential causes; etiological and pathophysiological mechanisms of ruptured plaque differ from other causes; and a correct treatment determines the prognosis ${ }^{2}$.

Cataldo et al. reviewed 28 patients with MINOCA from 2015 to 2019 and underwent cardiac magnetic resonance (CMR) and intravascular imaging (IVI) studies ${ }^{3}$. The majority were women $(76 \%)$ and the risk factors were hypertension (46\%), tobacco smoking (32\%), and dyslipidemia (32\%); $46 \%$ had an apical ballooning pattern. The cause of MINOCA was identified in $36 \%$ of cases, as plaque disruption (18\%), spontaneous dissection (11\%) and thrombus (7\%). CMR done in 50\% of patients showed stress cardiomyopathy (9), myocarditis (2) and transmural infarction (2). Plaque rupture and late transmural enhancement occurred in $23 \%$ of apical ballooning. MINOCA was more common in people with low risk factors, multi-image studies had better diagnostic precision, and mortality was associated with disruption of plaques ${ }^{3}$.

Santos et al. in 2019 reported a case of MINOCA in a 56-year-old smoker female with recent mental stress ${ }^{4}$. The diagnosis of AMI was confirmed by cardiac biomarkers elevation, and CMR indicating an ischemic etiology. The authors emphasized the up to $24 \%$ of type 2 AMI without electrocardiographic changes; while a segmental ventricular dysfunction may occur. They cited causes of coronary spasm, including cocaine and amphetamine use, pheochromocytoma, hyperthyroidism, Takotsubo cardiomyopathy, and increased vasoreactivity to sympathetic stimuli; as well as paradoxical embolism, increased cardiac demand, non-bacterial thrombotic endocarditis, antiphospholipid syndrome, and spontaneous coronary dissection ${ }^{4}$. Besides, they commented on the major role of CMR if coronary angiography does not reveal the diagnosis, because gadolinium identifies areas of reversible or irreversible ischemic injury and late enhancement reveals the presence of AMI-related fibrosis ${ }^{4}$.

The aim of the commented articles about MINOCA is to enhance the awareness of all the care health workers about this cardiac condition with a challenging diagnosis.

\section{REFERENCES}

1. Grigoli AA, ViccechiMFF. Epidemiologia e manejo dos pacientes diagnosticados com infarto do miocárdio sem obstrução coronariana (MINOCA): revisão integrativa. Colloq Vitae. 2020; 12(3): 74-81. DOI: https://doi.org/10.5747/cv.2020.v12.n3.v311.

2. Asil S, Barış VÖ, Geneş M, Taşkan H, Görmel S, Yıldırım E et al. Myocardial infarction with non-obstructive coronary artery disease, a retrospective cohort study: Are plaque disruption and other pathophysiological mechanisms the same disease? J Surg Med. 2021;5(1):50-4. https://doi.org/10.28982/josam.839523

3. Cataldo VP, Verdugo FJ, Dauvergne C, García A, Antileo P, Monsalve R, et al. Infarto agudo de miocardio sin enfermedad coronaria ateroesclerótica obstructiva: utilidad de las imágenes intravasculares y resonancia cardíaca em su diagnóstico. Rev Med Chile 2020;148: 1083-9. https://doi.org/10.4067/S0034$\underline{98872020000801083}$

4. Santos VM, Leite RGM, Daameche LNA, Mariotto WLC, Monte GU. Síndrome coronariana aguda sem obstrução significativa: relato de caso. Brasília Med. 2019;56:8-10. https://doi.org/10.5935/2236$\underline{5117.2019 v 56 a 03}$ 